\title{
PREVALENCE OF EXTENDED-SPECTRUM BETA-LACTAMASES-PRODUCING MICROORGANISMS IN NOSOCOMIAL PATIENTS AND MOLECULAR CHARACTERIZATION OF THE SHV TYPE ISOLATES
}

\section{Caio Fernando de Oliveira ${ }^{1}$, Adenilde Salla ${ }^{2}$, Valéria Maria Lara ${ }^{4}$, Alexandre Rieger ${ }^{3}$, Jorge André Horta ${ }^{3 *}$, Sydney Hartz Alves 4}

${ }^{1}$ Programa de Pós graduação em Ciências Farmacêuticas, Universidade Federal de Santa Maria, Santa Maria, RS, Brasil; ${ }^{2}$ Hospital Universitário de Santa Maria, UFSM, Universidade Federal de Santa Maria, Santa Maria, RS, Brasil; ${ }^{3}$ Departamento de Biologia e Farmácia, Universidade de Santa Cruz do Sul, Santa Cruz do Sul, RS; ${ }^{4}$ Departamento de Microbiologia e Parasitologia, Universidade Federal de Santa Maria, Santa Maria, RS, Brasil.

Submitted: March 14, 2008; Returned to authors for corrections: May 20, 2008; Approved: November 08, 2009.

\begin{abstract}
The emergence of Extended-Spectrum Beta-Lactamase (ESBL)-producing microorganisms in Brazilian hospitals is a challenge that concerns scientists, clinicians and healthcare institutions due to the serious risk they pose to confined patients. The goal of this study was the detection of ESBL production by clinical strains of Escherichia coli and Klebsiella sp. isolated from pus, urine and blood of patients at Hospital Universitário Santa Maria, Rio Grande Sul, RS, Brazil and the genotyping of the isolates based on bla SHV genes. The ESBL study was carried out using the Combined Disc Method, while Polymerase Chain Reaction (PCR) was used to study the bla SHV genes. Of the 90 tested isolates, 55 (61.1\%) were identified as ESBL-producing by the combined disk method. The bla SHV genes were found in $67.8 \%$ of these microorganisms. K. pneumoniae predominated in the samples, presenting the highest frequency of positive results from the combined disk and PCR.
\end{abstract}

Key words: ESBL, Enterobacteriaceae, Prevalence, PCR.

\section{INTRODUCTION}

Extended-spectrum beta-lactamases (ESBL) are enzymes that confer resistance to penicillins, cephalosporins of the first, second and third generations and aztreonam via hydrolysis of the antibiotics. ESBL are inactivated by beta-lactamase inhibitors such as clavulanic acid (10).

Escherichia coli and Klebsiella pneumoniae are the most common ESBL producing bacterial species, although detection of these enzymes has been observed in various other species of Enterobacteriaceae and Pseudomonadaceae (6). Patients with infections caused by ESBL-producing Enterobacteriaceae should not be treated with beta-lactam antibiotics due to the risks of therapeutic failure and increased infectiousness that could result in death (10).

Production of ESBLs is an important mechanism of betalactam resistance in Enterobacteriaceae (13). Early detection of multiresistant bacteria is important in defining therapies and for the isolation of patients, which is necessary to prevent the spread of these pathogens and also to prevent hospital-acquired (nosocomial) infections and outbreaks in the community (10, $15)$. 
Although presumptive, the phenotypical test for identification of ESBL based on disk-diffusion is the most common strategy used in microbiology laboratories in Brazilian hospitals. However, this method has serious limitations, as additional resistance mechanisms, like AmpC type beta-lactamases, can cause divergence in the results $(2,12$, 17). Only few studies in Brazil investigated the genotypic origin of ESBL, so there is little knowledge on the epidemiological aspects of the prevalence of these enzymes. This study aimed to evaluate the prevalence of ESBL producing bacteria in Hospital Universitário de Santa Maria, employing a phenotypic detection procedure based on the combined disk method and a genotypic method based on the detection of bla sHv gene using the polymerase chain reaction (PCR). The correlation between results obtained using the two methodologies was also evaluated.

\section{MATERIALS AND METHODS}

Microorganisms: A total of 90 isolates belonging to the Enterobacteriaceae family were collected from patients at Hospital Universitário de Santa Maria (HUSM), in Santa Maria, RS, Brazil. Isolates were collected over a 2-year period (April 2005 to September 2006) from urine, pus, and blood. The isolates were identified by conventional techniques and tested for probable presence of ESBL by the autoSCAN-4 system (Dade Behring).

Detection of ESBL by phenotypic method: The combined disk method for phenotypic detection was utilized using cefpodoxime $(10 \mu \mathrm{g})$, ceftazidime $(30 \mu \mathrm{g})$ and cefotaxime $(30 \mu \mathrm{g})$ disks, alone and in combination with clavulanic acid (10 $\mu \mathrm{g})$ (Oxoid; Basingstoke, UK). The tests were carried out in Mueller-Hinton agar (Merck; Darmstadt, Germany) and interpreted according to the standards established by the CLSI (Clinical and Laboratory Standards Institute) $(3,4)$. An increase of more than $5 \mathrm{~mm}$ in the diameter of the inhibition halos around disks containing clavulanic acid as compared to the diameters of around disks free of this inhibitor indicated ESBL activity. Klebsiella pneumoniae
ATCC 700603 and Escherichia coli ATCC 25922 were used as positive and negative controls, respectively.

Detection of ESBL by genotypic method: Polymerase Chain Reaction (PCR) was used for detection of the genes for the SHV family of ESBL enzymes. DNA extraction followed the method described by van Soolingen (14). The primers used for the amplification of the bla sHv gene were 5'-GGG TTA TTC TTA TTT GTC GC-3' and 5' -TTA GCG TTG CCA GTG CTC-3' (Integrated DNA Technologies, Inc. Coralville, USA), as described by Paterson (9). The MJ96+/MJ96G Thermocycler (Biocycler) was used for the amplification. The reaction conditions were: an initial denaturation temperature of $95^{\circ} \mathrm{C}$ for 5 minutes, followed by 35 cycles of $95^{\circ} \mathrm{C}$ for 45 seconds (denaturation), $59^{\circ} \mathrm{C}$ for 45 seconds (annealing) and $72^{\circ} \mathrm{C}$ for 1 minute (extension) with a final extension of $72^{\circ} \mathrm{C}$ for 7 minutes. The amplified product was submitted to electrophoresis in $1 \%$ agarose gel (BioRad) with ethyl bromide (Invitrogen) $(0.5 \mu \mathrm{g} / \mathrm{mL})$ for 1 hour (6 Volts $/ \mathrm{cm})$, and was visualized under UV light (312 nm) using an ECX Series Transilluminator (Vilber Lourmat) and photodocumented with a DP-001.FDC system (Vilber Lourmat).

\section{RESULTS}

Among the 90 isolates tested, the combined disk test indicated that $55(61.1 \%)$ isolates presented inhibition of clavulanic acid. The most common species presenting this activity were Klebsiella pneumonia (71.9\%), Escherichia coli (36.4\%) and Klebsiella oxytoca (25\%).Comparing the results of the combinations of cephalosporins with clavulanic acid, those involving cefpodoxime (87\%) and cefotaxime $(81 \%)$ were superior to those obtained when ceftazidime was combined with clavulanic acid (49.1\%) (Table 1).

PCR tests indicated that 61 isolates $(67.8 \%)$ presented the bla SHV ESBL gene, as determined by the presence of a 930-bp amplification product in agarose gel electrophoresis. These results indicate the prevalence of this family of ESBL in the HUSM (Fig. 1). The SHV genotype was observed in $78.1 \%$ of K. pneumoniae isolates, in $45.5 \%$ of E.coli isolates and in $25 \%$ of $K$. oxytoca isolates (Table 2). 
Table 1. Prevalence of ESBL producing isolates as determined by the Combined Disk test

\begin{tabular}{|c|c|c|c|c|c|}
\hline & & \multicolumn{4}{|c|}{ Combined Disk } \\
\hline \multicolumn{2}{|c|}{ Species } & Ceftazidime & Cefotaxime & Cefpodoxime & Total \\
\hline & n $(\%)$ & n $(\%)$ & n $(\%)$ & n $(\%)$ & n $(\%)$ \\
\hline K. pneumoniae & $64(71.1)$ & $21(45.6)$ & $39(84.8)$ & $40(87.0)$ & $46(83.7)$ \\
\hline E. coli & $22(24.4)$ & $5(62.5)$ & $5(62.5)$ & $7(87.5)$ & $8(14.5)$ \\
\hline K. oxytoca & $4(4.4)$ & $1(100.0)$ & $1(100.0)$ & $1(100.0)$ & $1(1.8)$ \\
\hline Total & $90(100.0)$ & $27(49.1)$ & $45(81.0)$ & $48(87.0)$ & $55(100.0)$ \\
\hline
\end{tabular}

Table 2. Frequency of the SHV genotype in the ESBL producing isolates

\begin{tabular}{lccc}
\hline & Species & & \multicolumn{2}{c}{ PCR } \\
\cline { 3 - 4 } & $\mathbf{n}$ & SHV + (\%) & SHV - (\%) \\
\hline K. pneumoniae & 64 & $50(78.1)$ & $14(21.9)$ \\
E. coli & 22 & $10(45.4)$ & $12(54.5)$ \\
K. oxytoca & 4 & $1(25.0)$ & $3(75.0)$ \\
\hline Total & 90 & $61(67.8)$ & $29(32.2)$ \\
\hline
\end{tabular}

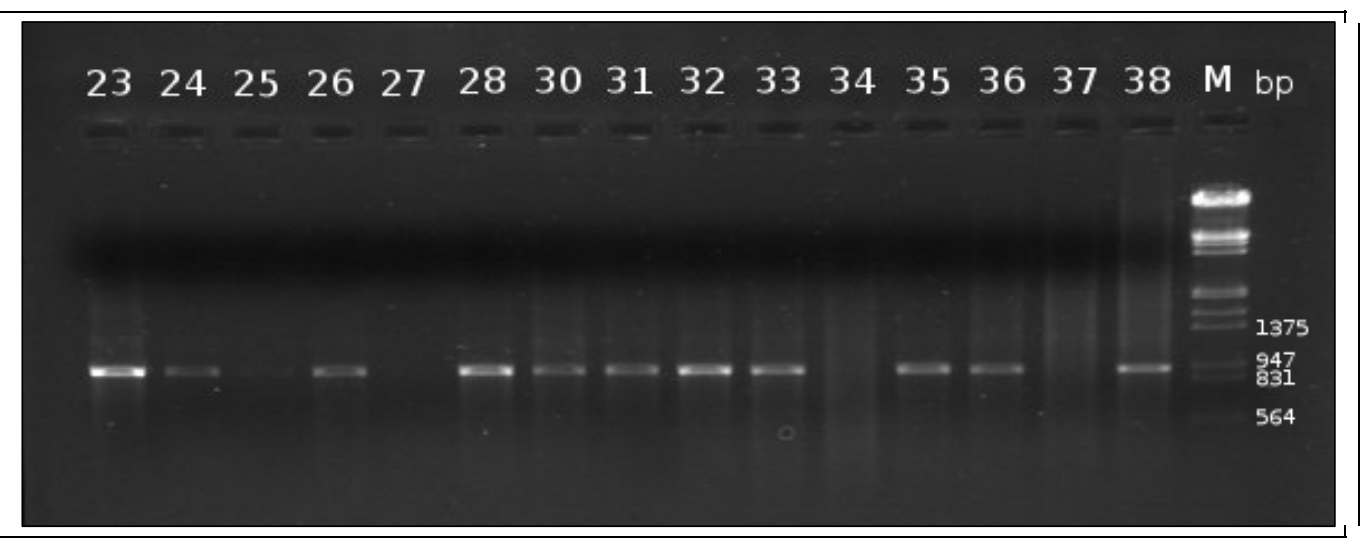

Figure 1. Agarose gel showing amplicons of isolates 23 to $38 . \mathrm{M}=$ DNA molecular size marker (PB-L Productos Bio-Lógicos) in base pairs (bp). 


\section{DISCUSSION}

The correct detection of ESBL producing microorganisms is a challenge for the laboratories, requiring not only phenotypic tests by also genotypic tests for all genes associated with beta-lactamase production. According to the majority of epidemiological studies on ESBL, K. pneumoniae and E. coli are the most common species implicated in this type of resistance. In Rio Grande do Sul, Freitas et al. (6) and d'Azevedo et al. (1) also observed that these two species were the most prevalent among ESBL producing microorganisms, confirming international multicenter studies $(7,8,12,13,17)$. These results are very important as $K$. pneumoniae is the most frequent gram-negative bacteria involved in hospital-acquired infections and nosocomial outbreaks $(5,6,11)$.

The use of three distinct substrates in the combined disk tests increased the sensitivity of the tests, and cefotaxime and cefpodoxime performed the best, despite the occurrence of non-coincident results. Because of the elevated percentages of ESBL-producing E. coli presenting low minimum inhibitory concentrations (MIC) of ceftazidime, Tofteland et al. (17) recommended the use of cefpodoxime alone or a combination of cefotaxime and ceftazidime as preferred substrates for ESBL detection. In this study, the frequency of ESBL-producing microorganisms detected by the ceftazidime disk was $49.1 \%$, a result substantially lower than the percentages detected by the cefpodoxime and cefotaxime disks. These results agree with those reported by Carter et al (2) who, using only cefpodoxime, obtained $100 \%$ sensitivity and specificity in ESBL detection among 180 isolates of beta-lactamases producing Klebsiella.

The use of phenotypic tests for the detection of ESBLproducing microorganisms remains an issue, causing a great deal of discussion and controversy. Some factors such as the production of different beta-lactamases by the same microorganism could lead to erroneous conclusions (13). Tests based on the detection of ESBL by PCR and isoelectrofocusing are more conclusive in defining ESBL production (16). In this study, the comparison of results from the combined disk test against the PCR results resulted in two types of discordance.
Nine isolates tested positive for ESBL in the phenotypic test but were negative in the PCR, which can be explained by the probable presence of ESBLs from the TEM, CTX-M or other ESBL families in these samples. However, 15 isolates presents the SHV family gene, but were negative in the phenotypic test. These results point to a probable detection failure in the test based on the inhibition of the enzyme by the clavulanic acid. Situations in which the inhibitory action of clavulanic acid can be masked include the coexistence of more than one enzyme that confers resistance, for example ESBL + AmpC type enzymes, changes in the pores of the cell membranes and TEM and SHV type beta-lactamases with a reduced affinity for betalactamases inhibitors $(13,16)$. Also, the production of different types of beta-lactamases (TEM, SHV, CTX-M, OXA) by the same microorganism can lead to erroneous phenotypic conclusions (13). In 2007, Tofteland et al. (17) reported that hyper-production of SHV-1 or SHV-11 can also be the cause of failure in ESBL detection when the combined disk method is used.

The combined disk method for phenotypic detection of ESBL production indicated a high prevalence of this type of resistance among samples taken at the HUSM (61.1\%). However, the detection of this type of resistence was even higher when PCR was used. In a scenario of increasing microbial resistance to antibiotics, this result corroborates the known limitations of the phenotypic methods, reinforcing the need for molecular methods such as PCR for identification of ESBL producing microorganisms.

\section{REFERENCES}

1. Azevedo, P.A.; Gonçalves, A.L.; Musskopf, M.I.; Ramos, C.G.; Dias, C.A. (2004). Laboratory tests in the detection of extended spectrum betalactamase production: National Committee for Clinical Laboratory Standards (NCCLS) screening test, the E-test, the double disk confirmatory test, and cefoxitin susceptibility testing. Braz. J. Infect. Dis., 8(5): 372-377.

2. Carter, M.W.; Oakton, K.J.; Warner, M.; Livermore, D.M. (2000). Detection of extended-spectrum $\beta$-lactamases in Klebsiellae with the Oxoid combination Disk method. J. Clin. Microbiol., 38(11): 4228-4232. 
3. Clinical and Laboratory Standards Institute/NCCLS. (2003). Performance Standards for Antimicrobial Disk Susceptibility Tests; Approved Standard-Eighth Edition. CLSI/NCCLS document M2-A8 [ISBN 156238-485-6]. Clinical and Laboratory Standards Institute, 940 West Valley Road, Suite 1400, Wayne, Pennsylvania 19087-1898 USA.

4. Clinical and Laboratory Standards Institute/NCCLS. (2005). Performance Standards for Antimicrobial Susceptibility Testing; Fifteenth Informational Supplement. CLSI/NCCLS document M100-S15 [ISBN 156238-556-9]. Clinical and Laboratory Standards Institute, 940 West Valley Road, Suite 1400, Wayne, Pennsylvania 19087-1898 USA.

5. Coque, T.M.; Oliver, A.; Pérez-Díaz, J.C.; Baquero, F.; Cantón, R. (2002). Genes Encoding TEM-4, SHV-2, and CTX-M-10 ExtendedSpectrum- $\beta$-Lactamases Are Carried by Multiple Klebsiella pneumoniae Clones in a Single Hospital (Madrid, 1989 to 2000). Antimicrob. Agents Chemother., 46(2): 500-509.

6. Freitas, A.L.P.; Machado, D.P.; Soares, F.S.C.; Barth, A.L. (2003). $\beta-$ lactamases de espectro ampliado em Klebsiella spp e em Escherichia coli obtidas em um hospital escola brasileiro: detecção, prevalência e tipagem molecular. Braz. J. Microbiol., 34(4): 344-348.

7. Jeong, S.H.; Bae, I.K.; Lee, J.H.; Sohn, S.G.; Kang, G.H.; Jeon, G.J.; Kim, Y.H.; Jeong, B.C.; Lee, S.H. (2004). Molecular Characterization of Extended-Spectrum Beta-Lactamases Produced by Clinical Isolates of Klebsiella pneumoniae and Escherichia coli from a Korean Nationwide Survey. J. Clin. Microbiol., 42(7): 2902-2906.

8. Luzzaro, F.; Mezzatesta, M.; Mugnaioli, C.; Perilli, M.; Stefani, S.; Amicosante, G.; Rossolini, G.M. (2006). Trends in Production of Extended-Spectrum $\beta$-Lactamases among Enterobacteria of Medical Interest: Report of the Second Italian Nationwide Survey. J. Clin. Microbiol., 44(5): 1659-1664.

9. Paterson, D.L. (2000). Recommendation for treatment of severe infections caused by Enterobacteriaceae producing extended-spectrum beta-lactamases (ESBLs). Clin. Microbiol. Infect., 6(9): 460-463.

10. Paterson, D.L.; Bonomo, R.A. (2005). Extended-Spectrum $\beta$-Lactamases: a Clinical Update. Clin. Microbiol. Rev., 18(4): 657-686.

11. Pereira, A.S.; Carmo Filho, J.R.; Tognim, M.C.B.; Sader, H.S. (2003).
Avaliação da acurácia de testes laboratoriais para detecção de amostras de Klebsiella pneumoniae produtora de betalactamase de espectro estendido. J. Bras. Patol. Med. Lab., Rio de Janeiro, 39(4): 301-308.

12. Perilli, M.; Dell'Amico, E.; Segatore, B.; De Massis, M.R.; Bianchi, C.; Luzzaro, F.; Rossolini, G.M.; Toniolo, A.; Nicoletti, G; Amicosante, G. (2002). Molecular Characterization of Extended-spectrum $\beta$-lactamases Produced by Nosocomial Isolates of Enterobacteriaceae from an Italian Nationwide Survey. J. Clin. Microbiol., 40(2): 611-614.

13. Sanguinetti, M.; Posteraro, B.; Spanu, T.; Ciccaglione, D.; Romano, L.; Fiori, B.; Nicoletti, G.; Zanetti, S.; Fadda, G. (2003). Characterization of clinical isolates of Enterobacteriaceae from Italy by the BD Phoenix Extended-spectrum beta-lactamases detection method J. Clin. Microbiol., 41(4):1463-1468.

14. Soolingen, D. van; Hermans, P.W.; de Haas, P.E.; Soll, D.R.; van Embden, J.D. (1991). Occurrence and Stability of Insertion Sequences in Mycobacterium tuberculosis Complex Strains: Evaluation of an Insertion Sequence-Dependent DNA Polymorphism as a Tool in the Epidemiology of Tuberculosis. J. Clin. Microbiol., 29(11): 2578-2586.

15. Sousa Junior, M.A.; Ferreira, E.S.; Conceição, G.C. (2004). Betalactamases de Espectro Ampliado (ESBL): um Importante Mecanismo de Resistência Bacteriana e sua Detecção no Laboratório Clínico. NewsLab, 63: $152-174$

16. Steward, C.D.; Rasheed, J.K.; Hubert, S.K.; Biddle, J.W.; Raney, P.M.; Anderson G.J.; Williams, P.P.; Brittain, K.L.; Oliver, A.; McGowan Jr, J.E.; Tenover, F.C. (2001). Characterization of Clinical Isolates of Klebsiella pneumoniae from 19 Laboratories Using the National Committee for Clinical Laboratory Standards Extended-Spectrum $\beta$ Lactamases Detection Methods. J. Clin. Microbiol., 39(8), 2864-2872.

17. Tofteland, S.; Haldorsen, B.; Dahl, K.H.; Simonsen, G.S.; Steinbakk. M.; Walsh, T.R.; Sundsfjord, A.; Norwegian ESBL Study Group. (2007). Effects of Phenotype and Genotype on Methods for Detection of Extended-Spectrum- $\beta$-Lactamase-Producing Clinical Isolates of Escherichia coli and Klebsiella pneumoniae in Norway. J. Clin. Microbiol., 45(1): 199-205. 